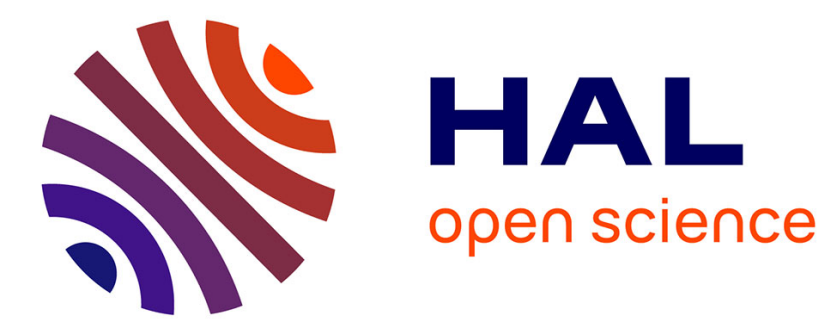

\title{
Yield design modelling of dry joint retaining structures
} Anne Sophie Colas, Denis Garnier, Jean Claude Morel

\section{To cite this version:}

Anne Sophie Colas, Denis Garnier, Jean Claude Morel. Yield design modelling of dry joint retaining structures. Construction and Building Materials, 2013, 41, pp 912-917. 10.1016/j.conbuildmat.2012.07.019 . hal-00942625

\section{HAL Id: hal-00942625 \\ https://hal.science/hal-00942625}

Submitted on 18 Feb 2014

HAL is a multi-disciplinary open access archive for the deposit and dissemination of scientific research documents, whether they are published or not. The documents may come from teaching and research institutions in France or abroad, or from public or private research centers.
L'archive ouverte pluridisciplinaire HAL, est destinée au dépôt et à la diffusion de documents scientifiques de niveau recherche, publiés ou non, émanant des établissements d'enseignement et de recherche français ou étrangers, des laboratoires publics ou privés. 


\title{
Yield design modelling of dry joint retaining structures
}

\author{
Anne-Sophie Colas ${ }^{*, a, 1}$, Denis Garnier ${ }^{\mathrm{b}}$, Jean-Claude Morel $^{\mathrm{a}}$ \\ ${ }^{a}$ Université de Lyon, Département Génie Civil et Bâtiment, École Nationale des Travaux Publics de \\ l'État, rue M. Audin, 69518 Vaulx-en-Velin cedex, FRANCE. \\ ${ }^{b}$ Université Paris-Est, UR Navier, École des Ponts ParisTech, 6-8 avenue Blaise Pascal, 77455 \\ Marne-la-Vallée cedex 2, FRANCE.
}

\begin{abstract}
This study presents an analysis of dry masonry retaining structures based on yield design theory : the structure stability is assessed using rigid block and shear failure mechanisms in the wall and its backfill. An application of this simulation on 2D scale-down brick and wood models is then addressed, showing close agreement between theoretical predictions and experimental results. Finally, the possibility of widespreading the study to periodic dry joint and dry-stone retaining structures is discussed.
\end{abstract}

Key words:

Dry joint masonry, retaining walls, yield design, scale-down experiments

\section{Introduction}

Masonry structures have received great interest over the past few decades, mainly due to the growing need for evaluation, maintenance and repair of historical architecture. Part of these masonry constructions were built dry

\footnotetext{
*Corresponding author: anne-sophie.colas@ifsttar.fr, tel: +33 140435 380, fax: +33 140436598.

${ }^{1}$ Present address: Université Paris-Est, IFSTTAR, SOA, 58 boulevard Lefebvre, 75732 Paris Cedex 15, FRANCE.
} 
or have experienced a loss of mortar due to aging and can now be considered as dry masonry structures.

A large number of studies have been dedicated to monumental constructions, but recent literature on retaining masonry structures is quite sparse. Modelling on masonry can be divided in two categories :

- macro-modelling where the masonry is considered as continuous and homogeneous and subjected to a classical behaviour law of mechanics of continuous media [1, 2, 3]; this approach provides immediate information on the structure but fails to take into account the characteristics of masonry internal behaviour;

- micro-modelling where the masonry is considered as heterogeneous; simulations differ depending on whether the medium is considered as continuous $[4,5,6]$ or discrete [7, 8]; this approach supplies plentiful information on the behaviour of the masonry but proves quite complex and time-consuming, and thus does not fit for practical purposes.

On the other hand, experimental studies are usually rare because difficult to undertake : in the literature can be found laboratory tests on periodic masonry [9] as well as recent on-site experiments on dry-stone retaining walls $[10,11,12]$.

The Department of Civil Engineering and Building (DGCB) of ENTPE concentrates on civil engineering materials and structures. It has been involved in the simulation of dry-stone masonry since 1998 with two theses dedicated to this theme $[13,14]$. The present work is part of this research field. 
This paper presents theoretical and experimental simulations to assess the stability of dry masonry retaining structures. First, a model based on yield design homogenization for dry masonry will be presented : this model enables to take into account the heterogeneity of the masonry while maintaining a pragmatic process. Then the simulation will evaluated on 2D scale-down experiments, with different parametric configurations in order to test its robustness and to apprehend dry masonry phenomenology. The widespread use of the model on full-scale periodic dry joint and dry-stone retaining constructions will finally be discussed. As a conclusion, future perspectives expanding on this work will be exposed.

\section{Yield design modelling of dry joint retaining structures}

The present work relies on yield design [15]; this theory enables to evaluate the ultimate bearing capacity of a structure, solely knowing its geometry, loading mode and yield criterion. This method was first devoted to soil mechanics, but expanding on this work, it has been proved that yield design could be applied to masonry $[16,17,18]$. The following section describes the procedure to model a dry joint retaining wall using this method.

\subsection{Hypotheses}

The system under investigation is constituted by the masonry retaining structure and its backfill. Three kinds of parameters of this system are now required to set up yield design. 


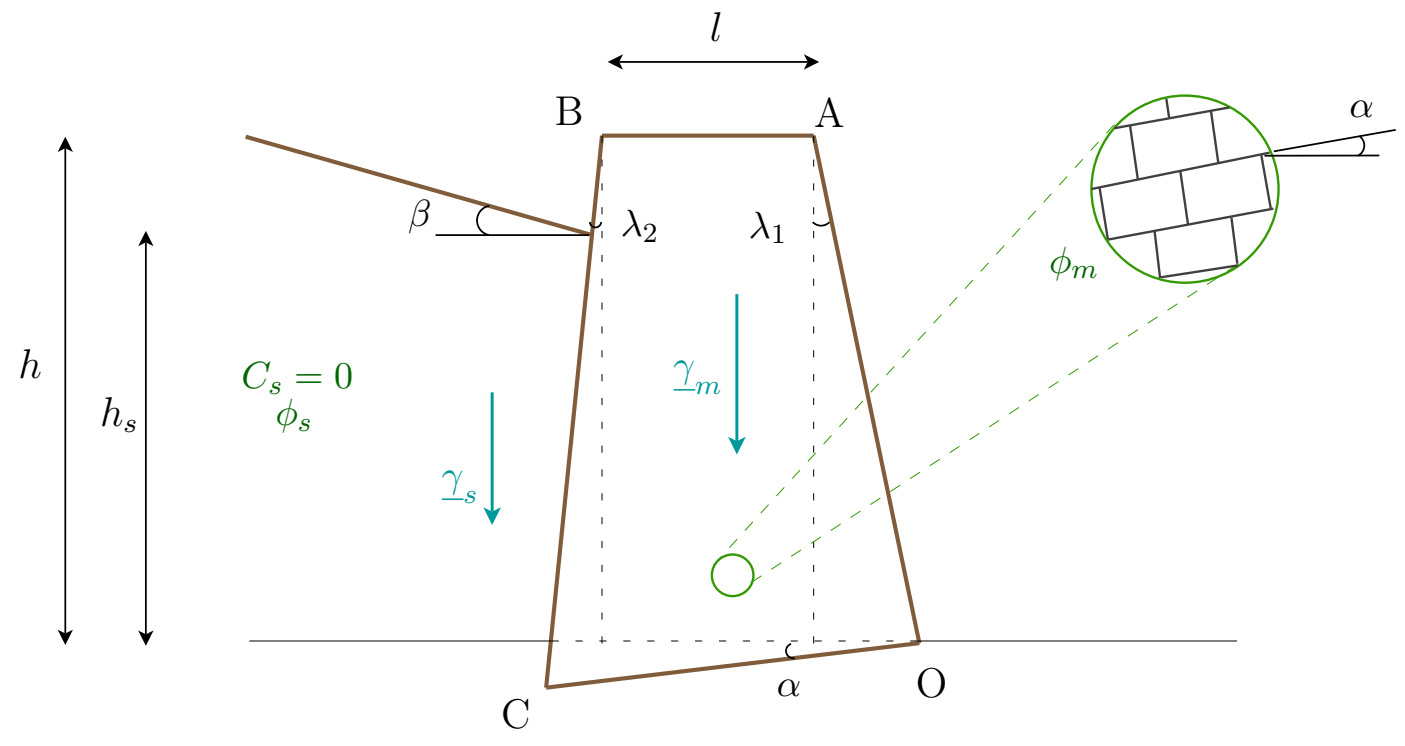

Figure 1: Dry-joint retaining wall modelling: hypotheses of geometry, loading and yield criterion.

\subsubsection{Geometry}

The wall is of height $h$ and of thickness at the top $l$, with a batter $\lambda_{1}$ and a counter-slope $\lambda_{2}$ (Fig. 1). The wall is assumed to be founded onto rigid bedrock, and the bed joints are inclined with an angle $\alpha$ from horizontal. The backfill will be considered as infinitely long, of height $h_{s}$, and its surface forms an angle $\beta$ with horizontal.

\subsubsection{Loading mode}

This system is only subjected to the respective unit weights of the wall $\underline{\gamma}_{m}$ and the soil $\underline{\gamma}_{s}$. 


\subsubsection{Yield criterion}

The yield criterion of the system depends on the wall and soil constituent materials.

The wall macroscopic yield criterion is calculated by a homogenization method for periodic media developed on by de Buhan and de Felice [16]. The joints will be assumed to have a purely frictional Mohr-Coulomb criterion, only depending on the block friction angle $\phi_{m}$, and the stones will be considered as infinitely resistant. The homogenization process (Fig. 2) enables to undertake a macroscopic stability assessment of the wall, now considered as a homogenized continuous medium.

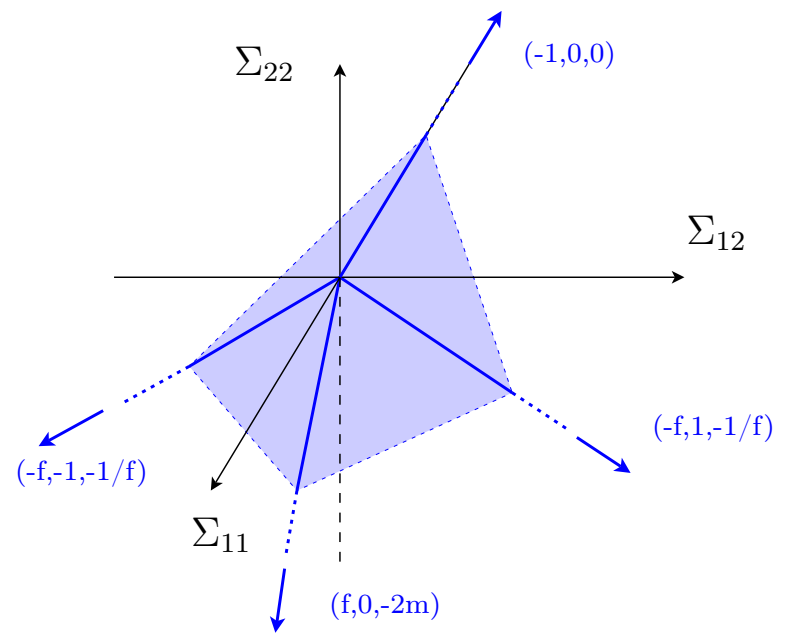

Figure 2: Yield criterion of homogenized dry joint periodic masonry depending on the block slenderness ratio $m$ and the tangent of the block friction angle $f=\tan \phi_{m}$.

The backfill submits to a purely frictional Mohr-Coulomb criterion, which friction angle will be noted as $\phi_{s}$. It has been decided that the cohesion of the soil would not be taken into account $\left(C_{s}=0\right)$ in order to simplify calculations. On the other hand, this hypothesis makes our design calculations better for 
safety.

The contact zone between the wall and its backfill is modelled by a MohrCoulomb criterion which friction angle equals $\phi_{s}$, the backfill friction angle. This hypothesis can be justified considering the roughness of the back face of the wall; it will be validated further on by the experimental tests.

\subsection{Yield mechanism}

The yield design upper-bound theorem consists in making the balance between the work of external force and the maximum resisting work for every kinematically admissible virtual velocity field.

In this study, the wall is intended to break from its toe along a failure line, which forms an angle of $\Psi_{m}$ from foundation (Fig. 3). The lower part of the wall remains fixed whereas the upper trapezium is given a velocity $\underline{v}_{m}$. The backfill is intended to follow a failure cone, which is given a velocity $\underline{v}_{s}$.

Two different virtual velocity fields will then be considered :

- a translation $\underline{\chi}_{m}$ in the wall and a translation $\underline{\chi}_{s}$ in the soil (Fig. 3a);

- a rotation $\underline{v}_{m}$ in the wall and a shearing $\underline{v}_{s}$ in the soil (Fig. $3 \mathrm{~b}$ ).

\subsection{Ultimate backfill height}

The ultimate backfill height $h_{s}^{+}$the wall can bear is the minimal height verifying that the work of external forces $W^{e}$ is lower than the maximum resisting work $W^{m r}$; this critical height only depends on the three kinds of parameters described above:

$$
h_{s}^{+}=f\left(h, l, \lambda_{1}, \lambda_{2}, \alpha, \beta, \gamma_{m}, \gamma_{s}, \phi_{m}, \phi_{s}\right)
$$




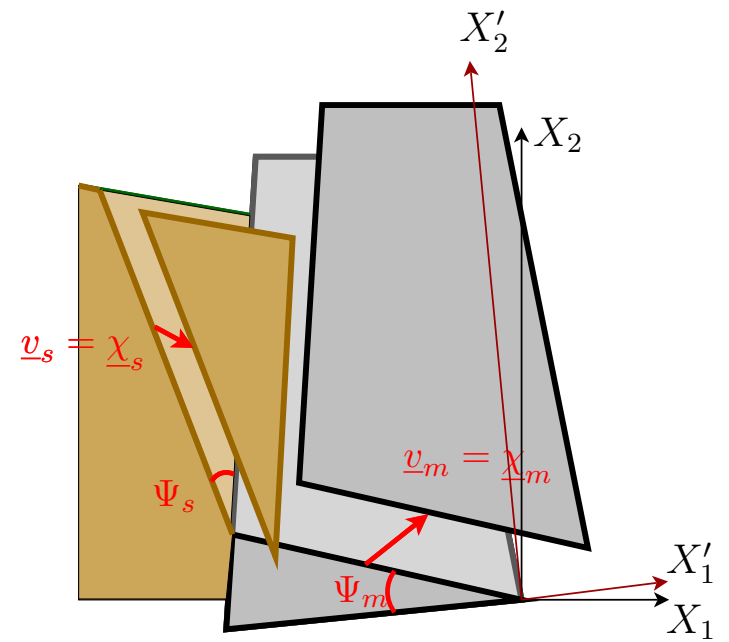

(a)

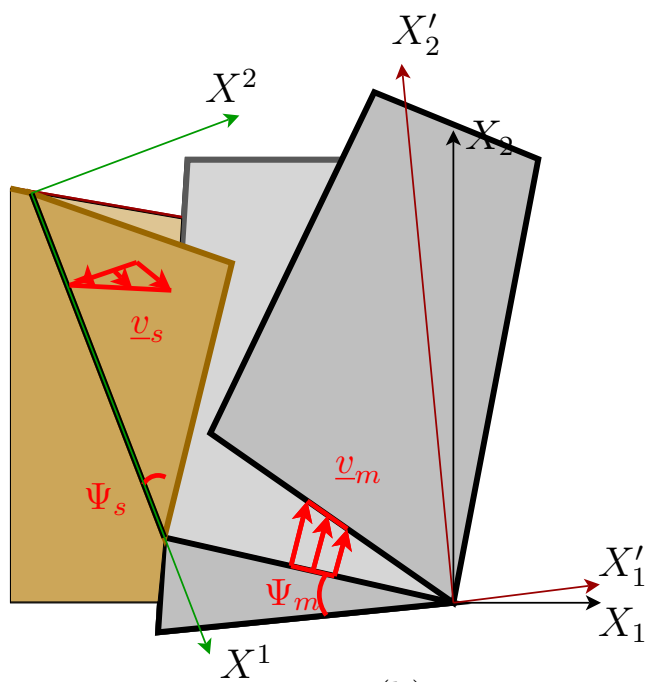

(b)

Figure 3: Virtual velocity fields : wall and backfill translations (a), wall rotation and backfill shearing (b).

Yield design gives indeed an indication on the failure characteristics. The velocity $\underline{v}_{m}$ provides the wall failure mode (sliding or overturning), and the failure plan inclination $\Psi_{m}\left(\Psi_{m}=\alpha\right.$ for sliding and it is variable for overturning).

Therefore, this method succeeds in taking into account the possible internal failure in the wall, and proves indeed easy to carry out, since requiring no programming and only few parameters.

\section{2D scale-down experiments of dry joint retaining structures}

The physical approach aims at assessing the consistence of the model. As they are quite easy to undertake and to repeat, they represent an attractive tool to test various parametric configurations. The campaign consists in the experiment of $30 \mathrm{~cm}$ high masonry structures built with brick and 
wood blocks and backfilled until failure with Schneebeli rods. These tests do not respect scaling effects, thus the scale-down models will be considered as fullfledged constructions but they can be used to evaluate dry joint masonry phenomenology and to prepare full-scale experiments.

\subsection{Experimental protocol}

\subsubsection{Constitutive elements characteristics}

In these experiments, it has been decided to represent the backfill soil by a Schneebeli material [19]. This designation refers to a set of rolls of different diameters which behaviour is similar to that of pulverulent soils but acting solely in two dimensions. The analogic backfill is thus constituted of small cylinders of duralium which are 3 to $5 \mathrm{~mm}$ of diameter and $6 \mathrm{~cm}$ long. Wilson-Jones [20] determined the soil friction angle $\phi_{s}=25^{\circ}$ using $30 \times 30 \mathrm{~cm}$ Casagrande shear tests.

The walls are made of plane-parallel blocks of the same length $(6 \mathrm{~cm})$ as that of the rolls and of section $2 \times 1 \mathrm{~cm}$. Two different types of materials were explored in order to evaluate the joint influence of wall unit weight $\gamma_{m}$ and friction angle $\phi_{m}$. The block friction angle was determined with $10 \times 10 \mathrm{~cm}$ Casagrande shear tests.

Geometrical and physical characteristics of the wall and the backfill are recorded in Table 1.

\subsubsection{Experimental device}

The scale-down models are self standing walls based on a rigid foundation of same material as that of the wall : they are built in staggered rows with the small elements previously described laid dry (Fig. 4). A minimum of five 
Table 1: Physical and geometrical characteristics of the system (in italic, the parameters which have been tested).

\begin{tabular}{|c|c|c|}
\hline & Brick & Wood \\
\hline Wall height $h(\mathrm{~cm})$ & 27.5 & \\
\hline Wall thickness $l(\mathrm{~cm})$ & 9 & 11 \\
\hline Wall batter $\lambda_{1}(\%)$ & $0,11,16$ & $0,9,12$ \\
\hline Wall counter-slope $\lambda_{1}(\%)$ & 0 & \\
\hline Joint inclination $\alpha\left(^{\circ}\right)$ & $-12,-9,-6,0,6$ & $-6,0,6,16$ \\
\hline Backfill slope $\beta\left(^{\circ}\right)$ & $0,10,15,20$ & $0,5,10,20$ \\
\hline Wall unit weight $\gamma_{m}\left(\mathrm{kN} / \mathrm{m}^{3}\right)$ & 18.4 & 7.1 \\
\hline Backfill unit weight $\gamma_{b}\left(\mathrm{kN} / \mathrm{m}^{3}\right)$ & 22.5 & \\
\hline Wall friction angle $\phi_{m}\left(^{\circ}\right)$ & 33 & 30 \\
\hline Backfill friction angle $\phi_{b}\left(^{\circ}\right)$ & 25 & \\
\hline Interaction friction angle $\phi_{b}\left(^{\circ}\right)$ & 25 & \\
\hline
\end{tabular}

blocks in the wall thickness is ensured in order to validate the use of homogenization. Each wall is then backfilled with $1 \mathrm{~cm}$ high layers of Schneebeli rods until failure. The backfill is sufficiently long $(65 \mathrm{~cm})$ so that it can be considered as semi-infinite to prevail from side effects.

\subsection{Parametric analysis}

Twenty-five tests were undertaken on varying geometrical and physical configurations of the wall and/or the backfill. For each type of block, the influence of the joint inclination $\alpha$, the wall batter $\lambda_{1}$, and the backfill slope $\beta$ was experienced. Each test is conducted with the same geometrical characteristics, except for the parameter tested (in italic in Table 1). Finally, the 


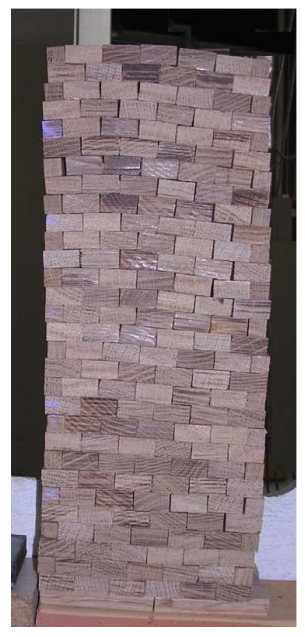

(a)

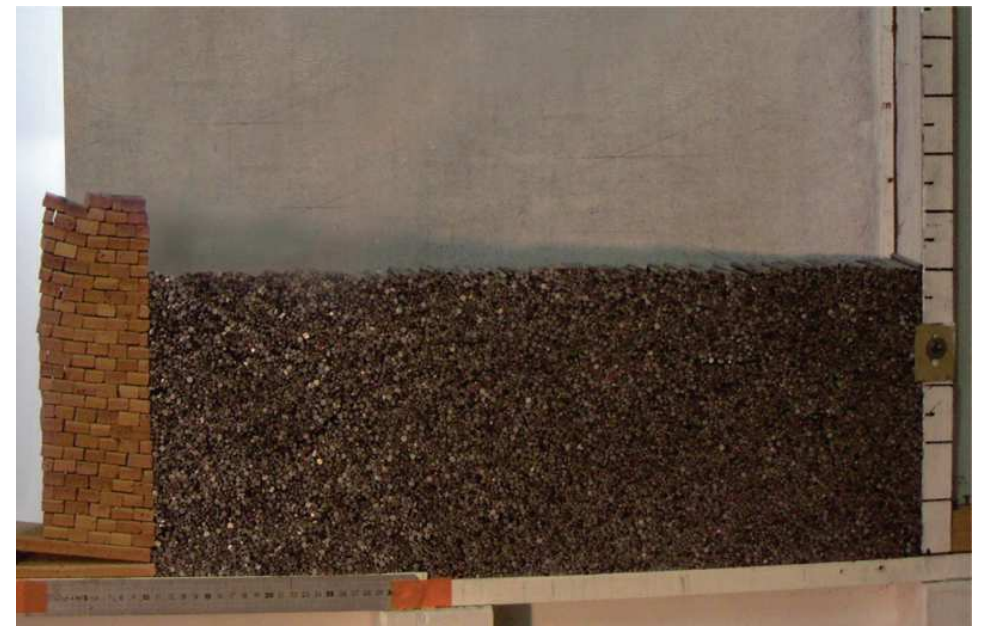

(b)

Figure 4: Experimental device : example of a dry joint wall of wood (a) and test on a brick wall backfilled with Schneebeli rods (b).

experimental failure height is compared to the ultimate height given by yield design.

This paper focuses on the first parametric test on the influence of joint inclination $\alpha$ on brick walls (Fig. 5); details on the other tests can be found in Colas et al. [21]. In this experiment, models are built with vertical faces and leaning joints (from -12 to $6^{\circ}$ ), and then loaded with a horizontal backfill until failure. Two different configurations have been tested for the back face of the wall:

- a blank face, which will be used for further experiments;

- a face covered with rolls, which ensures that the interface friction angle is equal to the soil internal friction angle.

This first experiment shows good qualitative agreement with yield design 
modelling, as the simulation succeeds in predicting the evolution of the ultimate height as well as the type of failure of the wall. Brick walls slide for $\alpha$ under $-12^{\circ}$ and overturn for $\alpha$ above $-6^{\circ}$ : for $\alpha=-8^{\circ}$, the failure mode combines sliding and overturning as predicted by yield design.

It has to be noted that the error rate is quite high when $\alpha$ is low: this configuration gets the wall very unstable and encourages errors due to experimental manipulation. This difference can also be accounted for by an overestimation of the brick friction angle.

Comparing tests with and without rolls at the interface shows that experimental results are closer to simulation predictions when interface are covered with rolls. The soil/structure friction angle may be lower than the soil internal friction angle. Yet, the low difference between the two configurations led us to validate the interface friction angle equal to $\phi_{s}$.

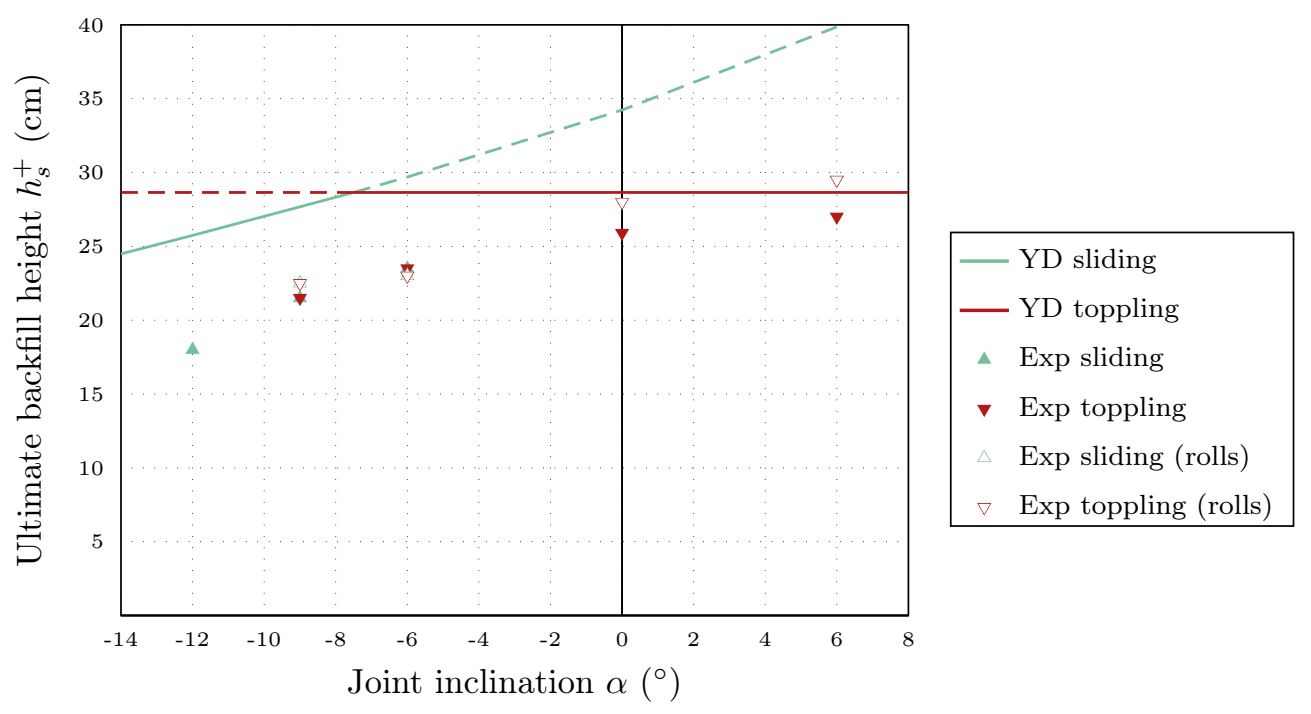

Figure 5: Theoretical and experimental ultimate backfill heights of brick walls $\left(\gamma_{m}=18.4\right.$ $\left.\mathrm{kN} / \mathrm{m}^{3}, \phi_{m}=33^{\circ}\right)$ depending on joint inclination $\alpha\left(\lambda_{1}=0 \%, \beta=0^{\circ}\right)$. 
The five other experiments confirm the good qualitative agreement between simulation and experiments. They indeed show that yield design succeeds in predicting experimental results with an error rate around $10 \%$. Further details can be found in Colas et al. [21]. Figure 6 presents theoretical ultimate heights depending on experimental results. It can be seen that the scatter plot is globally above the first bissector, meaning that theoretical predictions are higher than experimental results: this is quite coherent with the principle of upper-bound yield design theory which provides an upperbound limit of the ultimate height. On the other hand, the data are quite close to the first bissector, thus validating the simulation presented here. The furthermost points are those corresponding to the experiment on joint inclination for brick walls, for the reasons previously described.

Experiments show close agreement with theoretical predictions. The ultimate backfill height as well as the type of failure estimated by yield design correspond to those found by physical models with an error rate around $10 \%$, thus corroborating the hypothesis adopted for the wall/backfill interaction. These results also show that the model is able to take into account different materials and geometry. This experimental campaign enables the validation of the yield design simulation and help to prepare a full-scale field trial.

\section{Application to full-scale dry joint masonry structures}

The yield design simulation was developed to assess various types of dry joint retaining structures. Validation on 2D scale-models shows the robustness of the model toward parametric variations.

The quantitative results obtained in section 3 cannot be used to describe 


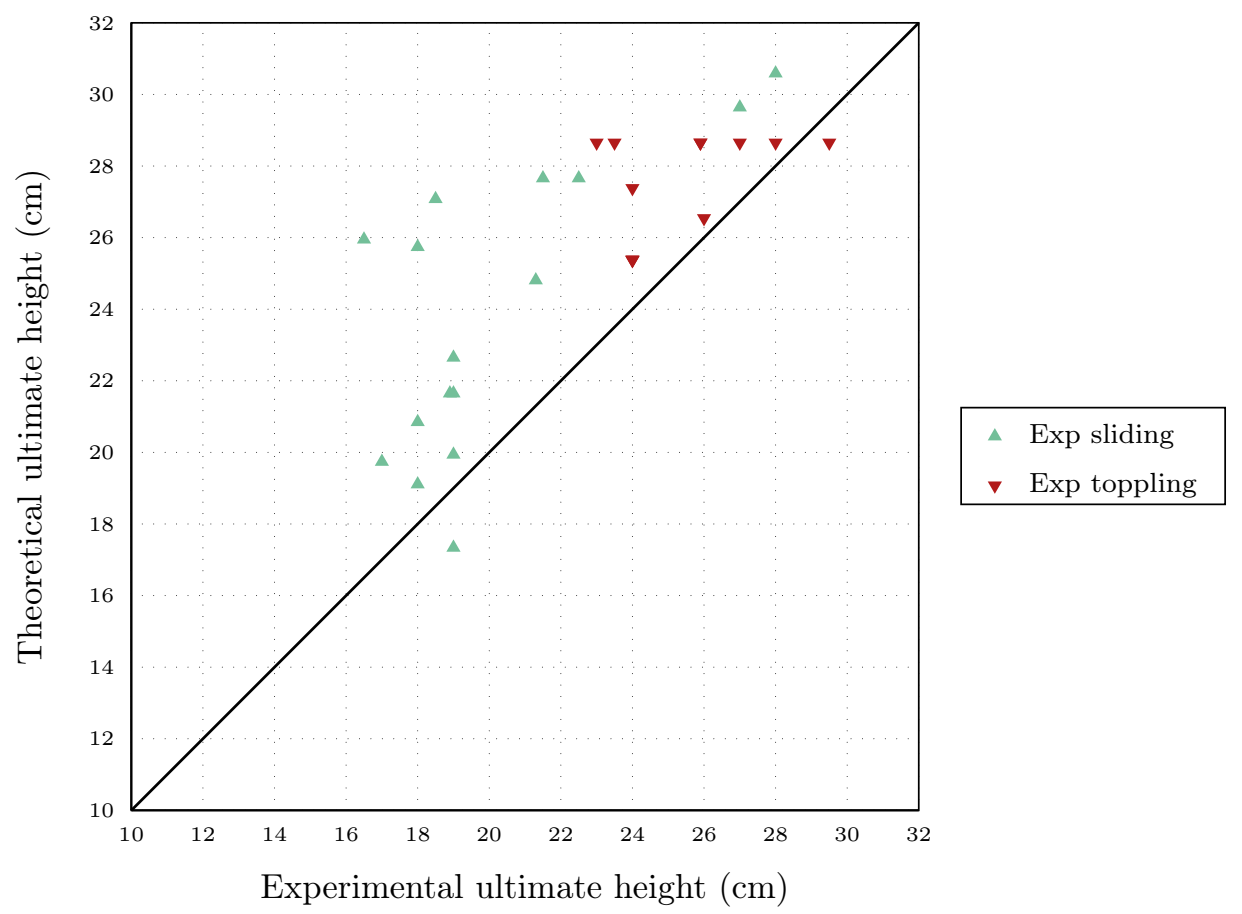

Figure 6: Outcome of the experimental campaign on 2D scale-models backfilled with Schneebeli rods.

full-scale structures as the experiments did not respect scale effects. Yet, the qualitative observations enable to describe dry joint periodic structure phenomenology. As a consequence of our parametric tests, the following trends can be identified:

- the inclination of bed joints toward the back face of the wall can prevent it from an early sliding;

- a batter on the wall front face reinforces its stability; besides, battered walls tend to fail by sliding rather than overturning;

- a growing slope of the backfill makes the wall unstable.

The yield design simulation presented above is meant to be used as a 
pragmatic tool to design dry-stone retaining wall. Dry-stone masonry consists in fitting interlocking stones without mortar to build a wall or a vault. It is a widely expanded form of construction, and an important heritage can be found all around the world. However, no structural design method has been validated until recently.

Simulating dry-stone construction by a regular and periodic medium makes it possible to take into account the strong heterogeneity of the structure while maintaining a pragmatic process. This hypothesis can be justified as regard to the apparent regularity of well-built dry-stone masonry (Fig. 7): actually, dry-stone construction practices recommend to build linear bed joints and to use small blocks of stone called pins to prevent blocks from rotating. Yet, the block irregularity leads to an important presence of void in the structure that can be taken into account in the simulation by a decrease of the wall unit weight. Villemus et al. [10] have measured the void percentage by weighing experimental dry-stone walls after testing : they estimated the percentage around $25 \%$ for walls built with large blocks of smooth limestone and $32 \%$ for walls constituted of thin blocks of schist.

Nevertheless, it is necessary to validate the model by comparisons with experimental data. The strong heterogeneity of the masonry and the specificity of the soil/structure interaction make it important to undertake fullscale experiments to provide qualitative as well as quantitative results. Thus experimental evaluation is meant to corroborate the qualitative observations presented here, provide complementary information-as for instance the wall void percentage, and finally validate the model as a practical tool to design dry joint retaining structures. 


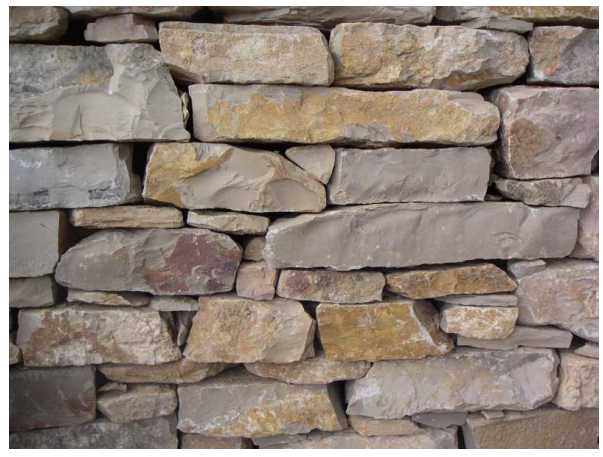

(a)

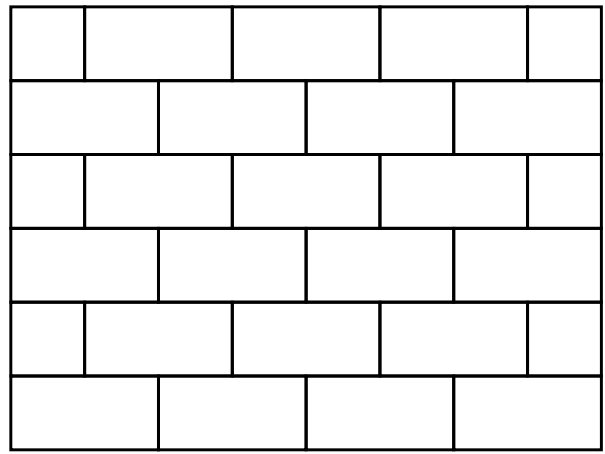

(b)

Figure 7: Comparison between dry-stone (a) and theoretical periodic masonry (b).

The authors have thus undertaken on site experiments on full-scale drystone walls (Fig. 8). The 2D scale-down experiments have been used to prepare the full-scale field trial, which had to be well-targeted considering its cost and its complexity. The aim of this campaign was to lead a dry-stone wall to overturn by means of pulverulent backfill. The bed joints of the wall were inclined toward the back face in order to prevent sliding. Indeed, the backfill was laid on its natural slope (maximum slope) in order to favour the wall failure. The wall geometry was designed using the model presented above. The experiments have been achieved [11]; comparisons with theoretical predictions are in process [22].

\section{Conclusions and perspectives}

This study has presented a pragmatic method to assess dry joint retaining structures thanks to yield design. A model based on yield design homogenization combined to its upper-bound kinematic approach has been established and then tested on 2D scale-down experiments. 


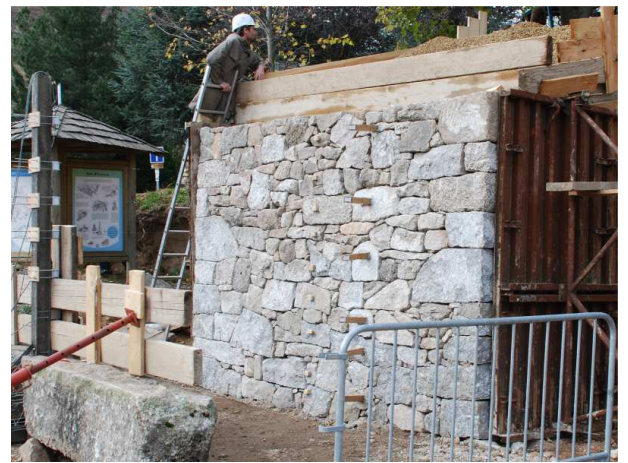

(a)

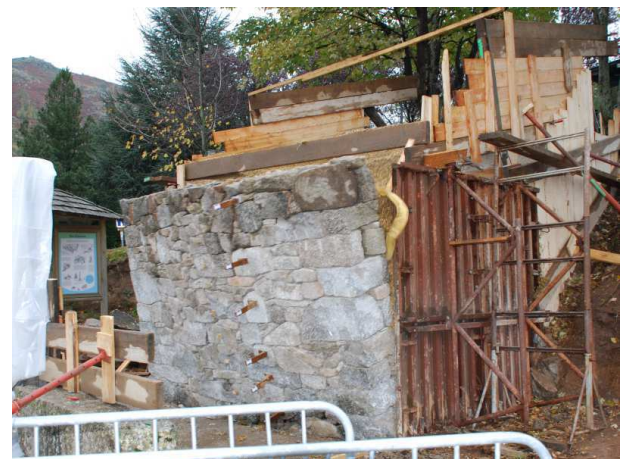

(b)

Figure 8: Full-scale field trials of dry-stone walls: preparation before experimentation (a) and overturning of the wall (b).

Comparing experimental results to theoretical predictions have proved the robustness of the model, thus validating the hypotheses taken into account. Indeed, it has provided interesting information on dry joint structure phenomenology. The scale-down experiments prove very interesting as they provide useful information while being relatively easy to undertake and to repeat. Yet, the results can be affected by the reduced size of the elements which make the experiment very sensitive to manipulation errors. On the other hand, the importance of scale effects on this type of structures prevents from using the quantitative results obtained to described full-scale constructions. Thus, the model needs to be confronted to experiments on full-scale structures to be validated.

Further perspectives on this work includes tests of the model on experimental data, and more especially on the results of full-scale field trials on dry-stone walls $[10,11]$. 


\section{References}

[1] J. Heyman, The stone skeleton, International Journal of Solids and Structures 2 (2) (1966) 249-279.

[2] F. Mola, R. Vitaliani, Analysis, diagnosis and preservation of ancient monuments: the St Mark's Basilica in Venice, in: $1^{\text {st }}$ International Seminar on Structural Analysis of Historical Construction, Barcelona (Spain), 1997.

[3] P. B. Lourenço, R. de Borst, J. G. Rots, A plane stress softening plasticity model for orthotropic materials, International Journal for Numerical Methods in Engineering 40 (21) (1997) 4033-4057.

[4] A. W. Page, Finite element model for masonry, A.S.C.E Journal of Structural Division 104 (8) (1978) 1267-1285.

[5] H. R. Lotfi, P. B. Shing, Interface model applied to fracture of masonry structures, Journal of structural engineering 120 (1) (1994) 63-80.

[6] A. Orduña, P. B. Lourenco, Cap model for limit analysis and strengthening of masonry structures, Journal of Structural Engineering 129 (10) (2003) 1367-1375.

[7] J. Lemos, Discrete element modelling of historical structures, in: International Conference on New Technologies in Structural Engineering, Lisbon (Portugal), 1997, pp. 1099-1106.

[8] A. Rafiee, M. Vinches, C. Bohatier, Application of the NSCD method to 
analyse the dynamic behaviour of stone arched structures, International Journal of Solids and Structures 45 (25-26) (2008) 6269-6283.

[9] P. B. Lourenço, D. V. Oliveira, P. Roca, A. Orduña, Dry joint stone masonry walls subjected to in-plane combined loading, Journal of Structural Engineering 131 (11) (2005) 1665-1673.

[10] B. Villemus, J. C. Morel, C. Boutin, Experimental assessment of dry stone retaining wall stability on a rigid foundation., Engineering Structures 29 (9) (2007) 2124-2132.

[11] A. S. Colas, J. C. Morel, D. Garnier, Full-scale field trials to assess dry-stone retaining wall stability, Engineering Structures 32 (5) (2010) $1215-1222$.

[12] C. Mundell, P. McCombie, A. Heath, J. Harkness, P. Walker, Behaviour of drystone retaining structures, Structures and Buildings 163 (1) (2009) $3-12$.

[13] B. Villemus, Étude des murs de soutènement en maçonnerie de pierres sèches, Ph.D. thesis, ENTPE-INSA de Lyon (2004).

[14] A. S. Colas, Mécanique des murs de soutènement en pierre sèche : Modélisation par le calcul à la rupture et expérimentation échelle 1, Ph.D. thesis, ENTPE-ECL (2009).

[15] J. Salençon, An introduction to the yield design theory and its application to soils mechanics, European Journal of Mechanics A/Solids 9 (5) (1990) 477-500. 
[16] P. de Buhan, G. de Felice, A homogenization approach to the ultimate strength of brick masonry, Journal of the Mechanics and Physics of Solids 45 (7) (1997) 1085-1104.

[17] A. Corfdir, Analyse de la stabilité des ouvrages en gabions cellulaires par la théorie du calcul à la rupture, Ph.D. thesis, ENPC (1997).

[18] K. Sab, Yield design of thin periodic plates by a homogenization technique and an application to masonry walls, Comptes Rendus Mécanique 331 (9) (2003) 641-646.

[19] G. Schneebeli, Une mécanique pour les terres sans cohésion, Compte rendus des séances de l'Académie des Sciences 243 (1956) 2647-2673.

[20] H. Wilson-Jones, Ouvrages renforcés par des géosynthétiques dans un modèle analogique plan, Ph.D. thesis, Université Joseph Fourier Grenoble I (1992).

[21] A. S. Colas, J. C. Morel, D. Garnier, 2D modelling of a dry joint masonry wall retaining a pulverulent backfill, International Journal for Numerical and Analytical Methods in Geomechanics 34 (12) (2010) 1237-1249.

[22] A. S. Colas, J. C. Morel, D. Garnier, Assessing the 2D behaviour of dry-stone retaining walls by full-scale experiments and yield design simulation, Géotechnique, under review. 